\title{
Ecotourism: Supply of nature or tourist demand?
}

\section{H. E. Perkins}

\section{Griffith University}

D. Grace

\section{Griffith University}

\section{Summary}

Although there is considerable consumer power resting in the hands of the individual tourist, in terms of the types of tourism products offered and the places being visited, there has been, surprisingly, little empirical research regarding tourists’ preferences for particular tourism packages and holidays. Furthermore, little is known in relation to tourist differences (or similarities) in preferences for, or motivation towards, mainstream as opposed to ecotourism tourist experiences. This study addresses this deficiency in the literature via empirical research involving a self-report survey of a sample of 255 tourists. The results indicate that a definite ecotourism market segment does seem to exist and that the motivations of mainstream tourists are qualitatively different from those of ecotourists, each defined by their preferences and interests. 


\section{INTRODUCTION}

Social researchers have reported that environmental issues are considered among the most urgent for humanity and the planet, and that a sizeable proportion of the developed world's population considers these issues to be a leading cause of concern (Dunlap, Van Liere, Mertig, \& Jones, 2000; Schultz, 2001; Wight, 1993). In line with this concern is growing worldwide interest in the natural environment and a "greening” of social processes. Furthermore, many organizations have now integrated sustainability and environmental accountability into their strategic focus (Page \& Dowling, 2002; Weaver, 2001a; Wight, 1993). The economic market has also recognized the potential that "eco" and "green" marketing campaigns have in selling almost anything.

In more recent years there has been a significant growth in travel offerings and tourismrelated advertising which makes reference to ecotravel, ecotours, ecoexpeditions, ecoadventures and ecotourism (Hawkins \& Lamoureux, 2001; Wight, 1993, 2001). The World Tourism Organization (WTO) declared in 1998 that ecotourism alone accounts for approximately one-fifth of all international travel (Wight, 2001). Furthermore, it has been suggested that ecotourism is growing faster than the tourism industry as a whole, with estimates of its rate of growth varying between 7\% and 30\% (Fennell, 2003; Page \& Dowling, 2002; Wight, 2001). However, estimates of market share and growth rate for ecotourism vary widely, and the industry has been marked by a lack of clarity and significant disparity of views in this regard (Fennell, 2003; Wight, 2001). It is likely that this apparent wide variation of opinions and reported statistics is probably due largely to the lack of a clear and consistently applied definition of ecotourism (Fennell, 2003; Weaver, 2006; Wight, 2001). Thus, corresponding estimates of the global economic value of ecotourism are also subject to 
some debate (Fennell, 2003). Suffice it to say that whatever the estimate of the ecotourism market or its true economic value, the ecotourism industry's contribution is nevertheless substantial, and many researchers agree that the demand is strong and growing (Hawkins \& Lamoureux, 2001; Page \& Dowling, 2002; Sharpley, 2001; Wight, 2001). This being so, there is considerable power resting in the hands of the individual tourist, in terms of both purchase of different types of tourism offerings and also demand for particular characteristics of the destinations visited. However, empirical research conducted on tourists’ preferences for particular tourism packages and holidays has largely been overlooked. Furthermore, little is known in relation to tourist differences (or commonalities) regarding preferences for mainstream (ie. mass tourism) as opposed to ecotourism tourism experiences, or the individual reasons for these choices and their perceived personal benefits. This study seeks to address this deficiency in current knowledge.

This paper will, firstly, provide evidence that tourists' higher levels of general interest in ecotourism (over more mainstream tourism) is related to explicit preferences for ecotourism type holiday packages, and also to tourist behavior. Secondly, this paper will present evidence that the reasons given for preferences and the perceived benefits of ecotourism type holidays versus mainstream type holidays are qualitatively different from each other. This provides some support for the notion that regular consumers of ecotourism do represent a distinct and authentic market segment.

\section{LITERATURE REVIEW}


Ecotourism has been most consistently defined as a form of nature based tourism, where the focus of the tourism experience is the natural environment and, sometimes, the cultural environment (Weaver, 2006). In addition, environmental learning and appreciation are expected outcomes of interaction between the tourist and the environment, and the goals include environmental, socio-cultural, and economic sustainability (Weaver, 2001a, 2001b, 2006; Weaver \& Lawton, 2002a). Embedded in this perspective is the notion that to understand and appreciate natural attractions implies a desire to ensure that the integrity of those attractions is not undermined (Rolston, 1991; Weaver, 2001a). This is a perspective that may not be shared by tourists engaged in some other forms of nature-based activity. Ecotourism can then be differentiated from other nature-based activities that are more leisureoriented, such as the " $3 S$ ” form of sun, sand and sea, as well as a range of adventure-oriented activities, such as trekking, climbing or rafting (Weaver, 2001a; Weaver \& Lawton, 2002b). The motivations to engage in these forms of nature-based activity may have more to do with enjoying a simple hedonistic experience of relaxing in the sun or seeking experiences that offer some degree of risk and personal challenge, with the natural environment representing the context rather than the focus of these experiences (Weaver, 2001a, p. 105).

\section{The Ecotourist}

Ecotourists can be defined as those more interested in ecotourism activities, perhaps as a result of an underlying pro-environmental psychological orientation. Systematic empirical research regarding ecotourists and their motivations is as yet limited, and what has been done is primarily descriptive in nature (Eagles, 1992; Fennell, 2003). For example, research has tended to categorize the types of activities tourists prefer to engage in as a basis for arguing that the ecotourist market is not homogenous (Fennell, 2003; Page \& Dowling, 2002; Wight, 2001). While this may be a somewhat useful observation from a marketing point of view, 
there is still relatively little known about tourists’ orientations towards the natural environment as an actual explanation of their choices or behavior (Fennell, 2003; Page \& Dowling, 2002).

The ecotourist can be defined by his/her interest in learning about and experiencing nature, and this interest is presumably coupled with a corresponding commitment to the sustainability of the natural environments that provide a context for leisure activities (Page \& Dowling, 2002). However as discussed previously, tourists who engage in ecotourism activities are probably likely to range from the dedicated or 'true' ecotourist to the occasional tripper who is visiting a destination to experience something new or 'trendy' (Page \& Dowling, 2002).

While some advocate that so-called true ecotourists hold a stronger pro-environmental orientation than the general population (Luzar, Diagne, Gan, \& Henning, 1995; Weaver \& Lawton, 2002a), others argue that there is no real empirical evidence to support the hypothesis that ecotourists are any more or less pro-environmentally inclined than the general population (Fennell, 2001; Sharpley, 2001, 2006). In fact, Sharpley (2006, p.9) says that there is little evidence to suggest that the ecotourist (i.e. those who are driven by a particular environmental interest or concern) really exists at all. He further argues that the demand for ecotourism is primarily a supply led phenomenon and that environmental interest and pro-environmental values are unlikely to predominate in the so-called ecotourist (Sharpley, 2006), and therefore all tourist experiences and the development of tourism products are, inevitably, dependent simply on the manner in which the individual consumes the tourist experience (Sharpley, 2006). 
Given the limited range of market related studies, together with poor definitional understanding of ecotourism and ecotourists, and the fact that ecotourist markets seem not to be homogeneous, the question remains, who is the ecotourist? Despite the large body of literature on ecotourism, previous market studies are mostly limited to destination area markets, to tour operator perceptions, or to more general studies of nature or adventure-based tourists. Moreover, Sharpley (2006) and Dolincar and Leisch (2008) argue that much of the academic attention directed at ecotourism to date has revolved around the nature of its definition (i.e. ecotourism), conceptual frameworks for studying ecotourism, destination management, environmental policy and protection of host communities, as well as destination case studies, that is, the nature and measures of supply, or as Sharpley (2006) puts it more bluntly, “the supply of nature” (p. 8), rather than identifying characteristics, preferences, and motivations of "broad 'origin’ populations” (Wight, 2001, p.37). In other words there has been a relative paucity of research into the motivational systems of the consumers who prefer ecotourism type products and who may also selectively purchase these on a frequent basis.

Some recent psychographic research into market segmentation tends to focus on studying one or more psychological variables, such as pro-environmental beliefs or attitudes, which are thought to drive consumer preferences and subsequent behavior (Fairweather, Maslin \& Simmons, 2005; Higham \& Carr, 2002; Zografos \& Allcroft, 2007). However, there has been very little research comparing the structure of tourism preferences and motivations for those preferences of so-called ecotourists with those of mainstream tourists. Therefore, in order to determine whether or not the ecotourist does exist as a distinct market segment based on underlying motivational systems, it seems worthwhile to examine tourists' personal preferences for different types of tourism experiences, rather than relying too heavily on 
simply collating a series of sampled behaviors (i.e. defining an ecotourist or a mainstream tourist simply by which tourism venue they have visited on the day of sampling).

As has already been argued, tourist visitation behavior on any particular day may be due to reasons other than personal preference and thus may not predict consistent choice for the same type of tourism experience over time. However, personal preferences together with the associated reasons for and perceived benefits of those choices (ie. basic motivations), are likely to be reflective of psychological variables such as value structures, goals and beliefs, and other related systems within a person's psyche, and thus predictive of more consistent behavior. Motivational systems tend to be highly stable and have been demonstrated to predict a variety of preferences, consumer choices and behaviors, including tourism (Acott, La Trobe, \& Howard, 1998; Luzar et al, 1995). Consumer preferences are likely to be dependent on deeper psychological motivations which transcend particular situational contexts and thus may influence behavior more consistently than context-specific choices. Therefore, if there is no relationship (or a positive relationship) between the preferences for mainstream and ecotourism holiday packages amongst tourists, then it could be suggested that these two different types of experiences both represent simply context-specific choices. In this case, the so-called ecotourist is simply responding to particular marketing campaigns and current trends for novel experiences which may happen to include those defined by the industry as ecotourism. Mainstream type experiences and ecotourism type experiences would then represent a single pool of interests from which the tourist consumer picks a particular experience to purchase at a point in time. On the other hand, if there is a negative relationship between the tourist preferences for mainstream holiday packages and ecotourism type holiday packages, then the ecotourist is alive and well. A negative relationship infers that preferences and motivations for each type of tourism, mainstream versus ecotourism, come from different 
and opposing sets of interests and those who prefer one type over another also represent different and distinct market segments based on those preferences and interests. Therefore, it is on this basis that the following research question is posed.

RQ1: To what extent is there a relationship between the preferences of tourists for mainstream as opposed to ecotourism holiday packages?

\section{Tourist Motivations}

There has been some limited research conducted in relation to the motivations of tourists concerning consumption of ecotourism but, to date, relatively few studies have collected primary data specifically for ecotourist segmentation purposes (Zografos \& Allcroft, 2007). In addition, some research findings, although informative, are extrapolated from data collected back in the 1980s (e.g., Eagles, 1992), while other research has been more concerned with profiling, or describing, different types of ecotourist based on broad based environmental beliefs for market segmentation purposes (Zografos \& Allcroft, 2007). However, even the psychological profiling of ecotourists seems to lack substantial empirical validation. While some answers concerning ecotourists' orientation towards the environment are beginning to emerge (Blamey \& Braithwaite, 1997; Fairweather, Maslin \& Simmons, 2005; Higham \& Carr, 2002; Zografos \& Allcroft, 2007), there is still an apparent lack of conviction as to whether the ecotourist really exists as a distinct segment (Sharpley, 2006). Sharpley (2006) argues that, to date, little evidence has been presented to support the notion that ecotourists are qualitatively different from more mainstream tourists in terms of their motivations for choosing ecotourism over other forms of tourism. Therefore, it is useful to determine if there is a distinct ecotourist market segment through the examination of not only tourists’ preferences for holidays, but also their expressed motivations for these preferences. 
If an ecotourist market segment is distinct, and indeed exists at all, there should also be qualitative differences between motivations for mainstream type holiday choices and the motivations expressed for ecotourism holiday experiences. Furthermore, one might also expect more commonality between the motivations for ecotourism type holiday choices, as a group, which would also be collectively distinct from the motivations given for the more mainstream activities. In other words, if the motivations for choice of ecotourism products are qualitatively similar to those of more mainstream products, then the growing emergence and market for ecotourism is simply an eco-sell phenomenon representing a fad that may die out in time. However, if the motivations for choice of ecotourism products are qualitatively different from more mainstream tourism products, then evidence is gained for concluding that

tourists are not simply subject to eco-sell, but rather that there is a genuine and distinct market segment of those who prefer ecotourism type experiences. In order to determine which of these alternatives is more valid, the following research question is posed.

RQ2: Are the motivations of tourists in relation to mainstream versus ecotourism holiday packages qualitatively different?

\section{METHODOLOGY}

Data were collected via convenience sampling at two different well known Gold Coast tourist venues. Details of the measurement instrument, data collection method and resulting sample are as follows. 


\section{Survey}

The data collection instrument was a self-administered survey. Firstly, respondents were asked to rank order their preferences of six tourism holiday packages, three of which were more mainstream holidays (i.e., sun and surf beach holiday; luxury resort holiday; nightlife, gaming and shopping holiday) while three were more nature-based type holidays (i.e. ecotourism, nature-based holiday; wildlife watching and/or photography holiday; volunteer ecotourism holiday package). There were no brochures or any other kind of information on hypothetical tourist attractions given to respondents. This decision was made to reduce the likelihood that particular marketing approaches or other detailed venue information might unduly influence respondents’ stated preferences. Respondents were given the following instruction: "If all of the following 6 tourism packages were similar prices and you had your choice, what would be your preference in order from 1to 6? Please rank the following packages from $\underline{1}$ being your first preference or most preferred, $\underline{2}$ being your second preference, and so on... to $\underline{6}$ being your last preference or least preferred package.” Respondents were asked to consider the holiday packages (under the assumption that all holidays were of a similar price) and rate them from their first (1) to their sixth (6) preference. Secondly, respondents were then asked to answer one further open-ended question concerning the reasons they had chosen their first preference. In addition, the Ecotourism Interest scale (EI) developed and tested by Juric, Cornwell and Mather (2002), was included in the field instrument as a check for consistency between self-reported general interest in ecotourism (as measured by the EI) and respondents' stated preferences for holiday type. The EI consisting of 7 items (eg. wilderness and undisturbed nature; national parks; world heritage status areas; tropical forests and indigenous bush; lakes and streams; etc.), was randomly interspersed with 8 additional items pertaining to more mainstream type common tourist interests (e.g. shopping; sun and surf; exciting nightlife; wine/ food tasting; historical sites/ museums, etc.). 
Respondents were asked to rate the importance of each of the total of 15 activities ( 7 from the EI plus 8 mainstream activities) when choosing a holiday, trip or attraction on a scale from 1 (not at all important) to 7 (extremely important). Interspersing the items of the EI with other mainstream type items was to minimize the chances of response pattern bias amongst respondents. In addition, respondents were asked to indicate their level of agreement (from 1 strongly disagree to 7 strongly agree) with the following three statements pertaining to consideration for environmental sustainability in tourism:

"I believe I should definitely consider my impact on the earth and other cultures when I make my travel choices"; "As a tourist it is very important to me that tourism products, services and venues are part of a similar 'green' accreditation system to the one described above” (Green Globe ${ }^{\mathrm{TM}}$ definition was presented); and "I would choose a tourism product or service which adopts a "green" accreditation system over one which does not if the choice is available”.

\section{Data Collection}

As the population of interest was tourists over the age of 18, two popular Gold Coast tourist attractions were selected as the data collection locations. The two locations were chosen on the assumption that they might attract very different segments of tourists. For example, the first location or venue is Seaworld, an iconic theme park tourist attraction located near to the beach, up-market shopping precincts, restaurants, luxury hotels and resorts. It was, therefore, assumed that this theme park may attract more tourists interested in mainstream type activities. The second location chosen, O’Reilly’s Rainforest Retreat in the World Heritage Lamington National Park, has advanced ecotourism accreditation status. Advanced ecotourism accreditation status is assigned by the Nature and Ecotourism Accreditation Program (NEAP) and is awarded to those venues which have achieved best practice in areas such as ecological sustainability, natural area focus and experience, opportunities for understanding and appreciating nature, contribution to conservation, working with local 
communities, sensitivity towards different cultures especially indigenous culture, client satisfaction, and responsible marketing practices (Ecotourism Australia, 2008). Because of this it was assumed that this venue would likely attract tourists who were more interested in nature based attractions and activities, and also learning about nature.

A convenience sampling approach was the chosen method of data collection at both of these locations, mindful of minimizing any inconvenience to respondents during their holiday experience. This involved the researcher, firstly, approaching potential respondents to elicit interest in the research project. In addition, all participants were presented with a complimentary drink voucher valued at $\$ 3.00$. Offering incentives to participants is recommended as an effective strategy not only to increase response rates (Thomas, 1999), but also to make respondents feel morally obligated to truthfully complete the survey (Burns and Bush, 1995). Those willing to participate were then seated within the vicinity of the researcher to complete the survey. This process resulted in a response rate of approximately 30\% from the initial sample approached, and a final sample of 255.

\section{Sample}

Data were gathered from the sample of 255 tourists of which $42 \%$ were male and $58 \%$ female. The average age was 41 years, ranging from 18 to 75 years old, and $73 \%$ were Australian born, with a further 10\% born in the United Kingdom, and 4\% in New Zealand. The remaining 13\% were born in some sixteen other countries from around the world.

\section{RESULTS}


Rankings of each of the six tourism choice packages were recorded and are detailed in Table 1. The results indicate that the beach holiday package was the most popular preference, with approximately $31.5 \%$ of all respondents indicating this as their first preference. The next most popular, and a close second, was the luxury resort package accounting for approximately $28 \%$ of first preferences. Wildlife watching and nature-based ecotourism were the next two most popular accounting for $19 \%$ and $15.5 \%$ of first preferences respectively. Volunteer ecotourism (i.e. paying for a holiday where one volunteers to work for environmental conservation) obtained approximately $4.5 \%$ of first preferences. The nightlife, gaming and shopping package accounted for only about $1.5 \%$ of first preferences. In summary, while mainstream tourism activities were chosen as first preference by approximately $61 \%$ of the respondents, more than a third (39\%) of respondents chose ecotourism and nature type holiday packages as their first preference.

\section{--- Insert Table 1 Here ---}

\section{General interest in ecotourism and ranked holiday preferences}

In order to determine if general interest in ecotourism, as measured by the EI, was related to holiday preferences Spearman's rho correlations were calculated using the preference rankings for all holiday types and average score on the EI. General interest in ecotourism was significantly associated with preference for ecotourism type holidays, and less interest in mainstream type holidays (see Table 2). These results provide evidence of the validity of the EI as a predictor of tourist preferences for ecotourism type holiday experiences, and also lend support for the usefulness of using preferences for particular holiday types as one measure of identifying the potential ecotourist market segment. 


\section{Relationship between actual tourist behavior, general interest in ecotourism, and holiday preferences.}

Evidence that the Ecotourism Interest scale (EI) is significantly associated with a preferences for ecotourism type holidays has been presented in the foregoing section, but it is useful to determine if the EI can also be demonstrated to be a significant predictor of actual tourist visitation behavior in this sample. In spite of the fact that there were almost twice as many tourists sampled at the mainstream venue $(\mathrm{N}=162)$ as sampled at the ecotourism venue (N=93), scores on the EI were indeed significantly predictive of actual visitation behavior $F$ $(1,252)=13.95, p=.000, t=3.74, p=.000$. Those who expressed higher levels of general interest in ecotourism were also significantly more likely to be visiting the ecotourism venue on the day of sampling. This result is consistent with previous research which found the EI to be a useful predictor of behavior (Juric et al, 2002), and therefore provides some further evidence of the validity of Ecotourism Interest scale (EI).

In order to determine if there was a difference between those who were sampled from the ecotourism venue and the mainstream venue in terms of their preferences for holiday types, a Chi-square analysis was employed. Results are summarized in Table 3. Those who were sampled at the ecotourism venue were generally more likely to prefer the ecotourism type holidays, and less likely to prefer the mainstream type holidays. The opposite pattern was evident in tourists sampled at the mainstream venue. It should be noted that both the volunteer ecotourism holiday and the nightlife, gaming and shopping holiday were the least popular with all respondents; however the response patterns evident with the other holiday 
choices were also evident with these holiday types, even though the trends were not significant.

\section{--- Insert Table 3 here ---}

The full pattern of preferences for ecotourism holidays in particular were examined in more detail, and Figure 1 graphically illustrates the opposing patterns of ranked preferences (i.e. 1st to 6th) which emerged between tourists sampled at each of the two different venue types (i.e. Seaworld mainstream venue, versus O’Reillys’ Rainforest Retreat ecotourism venue).

\section{--- Insert Figure 1 here ---}

The foregoing results collectively provide evidence that there seems to be a difference between those who express more general interest in and preference for ecotourism type and those who prefer mainstream type holiday experiences in terms of both holiday preferences and actual visitation behavior. In order to determine the nature and extent of these differences, and thus address RQ1 and RQ2, the following analyses were undertaken.

\section{Relationships between the ranked preferences}

In order to address RQ1, relationships between the ranked preferences were computed via Spearman's rho rank order correlations (refer Table 4 for these results). The results indicate that all correlations except one (between M1 and M2) are significant. In summary, the three ecotourism type packages (i.e. ecotourism nature-based; wildlife watching; and volunteer ecotourism) are all negatively related to the three mainstream type packages (i.e. sun \& surf or beach holiday; luxury resort holiday; and nightlife, gaming and shopping holiday). Those who tended to rank the former packages as more desirable tended to also rank the latter packages lower, or less desirable. There was also a positive relationship between all the 
ecotourism packages in terms of their relative preference rankings; those who ranked one of the ecotourism choices highly tended to also rank the others of this type highly. Generally, the same was true of the non-ecotourism packages, except for there being no relationship between sun and surf or beach holiday preferences and preferences for luxury resorts.

\section{--- Insert Table 4 Here ---}

The responses to the open ended questions addressing RQ2 were analyzed for meaningful content, and a tally was taken of the number of common thematic words or phrases used in the responses for each question. These tallies were organized into a form of linguistic grid for each question, cross-referencing the content theme by the preferred tourism package.

\section{Tourist motivations}

The pattern of results revealed that some distinct qualitative differences emerged between the six holiday packages (refer Table 5). For the sun and surf or beach holiday (M1), the major themes of fun, family friendly/ safe for children, enjoyment of the sun, warmth and surf, and relaxation were evident from the data. The luxury resort package (M2) resulted in strong themes which revolved around relaxation, escape from work or life pressures, and pampering (being waited on). The mention of pampering and being waited on was unique to the luxury resort package choice. The nightlife, gaming, and shopping package (M3) resulted in only one response "love spending money". In summary, the three mainstream type holiday preferences seem to revolve around relatively hedonistic pleasures, except for the family theme in regard to the beach holiday choice. 
Conversely, examination of the results for the three ecotourism type holiday preferences revealed that the themes which emerged from the data were distinctly different from those of the other three tourism packages. Motivations in relation to the ecotourism packages included a love for nature and wanting to be immersed in nature, education or learning about nature, and a slower pace of life. Volunteer ecotourism had an additional relatively unique theme, that of making a personal contribution, spiritual development or the ability to actively participate in conservation (freq $=11$ ). Thus, these results indicate that the reasons tourists prefer ecotourism type holidays appear quite different from those for other types of tourism, and furthermore seem more focused on concerns beyond mere hedonistic pursuits.

\section{Support for environmental sustainability in tourism}

Spearman's rho correlations were calculated to assess the relationships between holiday preferences and support for green accreditation of tourism products and services, and need for consideration of one's personal impact on the environment and cultures when making travel choices. Preferences for the ecotourism type holiday packages were significantly associated with stronger support for green accreditation, $r_{\mathrm{s}}=.29$ to $r_{\mathrm{s}}=.24$ (all significant at .001), with increased likelihood of purchasing an accredited product over one that was not, $r_{\mathrm{s}}=.28$ to $r_{\mathrm{s}}=$ .26 (significant at .001), and also more agreement that one should definitely consider one’s personal impact in making travel choices, $r_{\mathrm{s}}=.25$ to $r_{\mathrm{s}}=.20$ (significant at .001 and .01 ). Furthermore, higher levels of general interest in ecotourism were even more strongly related to support for green accreditation $r=.50$, willingness to purchase accredited products $r=.44$, and willingness to definitely consider personal impact on the environment in making travel choices $r=.43$ (significant at .001). 
In contrast, preferences for mainstream type holidays were all significantly associated with less support for green accreditation, $r_{\mathrm{s}}=-.30$ to $r_{\mathrm{s}}=-.20$ (significant at .001 and .01 ), less likelihood of purchasing accredited products, $r_{\mathrm{s}}=-.29$ to $r_{\mathrm{s}}=-.23$ (significant at .001), and less willingness to consider personal impact in making travel choices, $r_{\mathrm{s}}=-.26$ to $r_{\mathrm{s}}=-.19$ (significant at .001 and .01).

Thus, the pattern of results in terms of the apparent fundamental differences between preferences and motivations for ecotourism vis-à-vis mainstream tourism has been consistent across all of these analyses.

\section{A note on demographics}

In this study, preferences for particular holiday packages were not dependent on gender, nor was general interest in ecotourism. Age also had no relationship with general interest in ecotourism, although age was significantly associated with a preference for ecotourism type holidays $r=.26, p<.001$, and also with less inclination for nightlife, gaming and shopping holidays $r=-.24, p<.001$.

\section{DISCUSSION}

Sharpley (2006) has concluded that ecotourism is more appropriately considered as a "supply led market niche” (p. 19), and that there is little to distinguish ecotourists from mass or mainstream tourists. However, if this were so, one would expect there to be little relationship, or even a positive relationship, between preferences for ecotourism type experiences and mainstream type experiences, and furthermore motivations for preferences 
for each of these two types of experiences could be expected to have more in common than differences between them. However, the opposite is evident with this sample of tourists, in that the preference rankings for mainstream type experiences are negatively related to those of the ecotourism type experiences. If people tended to rank ecotourism, wildlife tourism, and volunteer ecotourism highly, they tended to rank beach holidays, luxury resort holidays, and nightlife, gaming and shopping lower. The converse was also true. In addition, the motivations for ecotourism experiences were qualitatively distinct from those of mainstream experiences. Moreover, and somewhat surprisingly, the motivations for ecotourism type experiences expressed in this study seem entirely consistent with the key themes expounded in the agreed definitions of ecotourism, namely nature as the focus of the experience, environmental education, and environmental conservation. This result seems particularly interesting given that definitions of ecotourism, including the three key elements of those definitions, are principally driven by the industry and not by the consumer, and that many consumers of those experiences may not even be aware of the key components of the industry definition in any explicit sense.

It is also interesting to note some consistency in these results with previous ecotourism literature (Page \& Dowling, 2002), and especially in regard to the negative relationship between the ecotourism type holiday preferences and the sun and surf beach holiday preferences (also a nature based experience). Weaver (2001) states that the difference between ecotourism and mainstream sun and surf or "3S" (sun, sea, sand) experiences is that, in the former, nature is the focus, whereas, in the latter, nature is purely the context in which more hedonistic activities happen to take place. The findings here confirm this notion, as a negative relationship between all three ecotourism packages and the sun/surf beach package were strongly evident. 
Moreover, the fundamentally different pattern of results in terms of preferences and motivations for the two different types of holiday experiences is also evident in the levels of support from respondents for environmental and cultural sustainability issues relevant to tourism. Tourists who preferred mainstream type experiences expressed less support for environmental sustainability in their travel decisions than those who preferred ecotourism type experiences, thus strengthening the argument that these represent distinct market segments.

From a marketing and industry perspective it is important for marketers and policy makers in tourism to be able to identify psychological variables as motivators of tourist choices (McKenzie-Mohr, 2000). Differences in those variables may assist in accurately defining particular tourist markets, and tourism packages of experiences can then be tailored to better suit the needs, motivations and expectations of the tourists within those markets (Fennell, 2001, 2003). While not conclusive, the findings may suggest that the growth of ecotourism type tourism experiences could be somewhat demand driven, and not simply a supply driven phenomenon. Further validation of this claim needs to be addressed in the future. However, the so-called ecotourist, defined by his/her interests and preferences, does appear to exist. If so, this means that marketers and service providers should make sure that each of the three elements of ecotourism (i.e. focus on nature, environmental education, and environmental conservation) are not only appropriately addressed but must be seen by potential consumers to be addressed. Relevant green accreditation systems overtly coupled with an attraction's brand image may possibly be more important than some providers are willing to admit. 


\section{LIMITATIONS}

As with all research, it is important to acknowledge and learn from the limitations of the study. The limitations of this study are discussed to clearly establish the boundaries, rather than to negate the findings of this study, as well as serve to identify future avenues for research. Firstly, it is acknowledged that any survey-based method, including that adopted in this study, involves some measurement error. However, given that respondents were able to respond openly (via an open ended question) about their motivations towards tourist packages, and completely anonymously, every attempt was made to reduce any measurement error as far as possible. Secondly, as data were collected from tourist attraction venues in the south-east region of the state via a convenience sampling approach, it could be suggested that generalisability beyond this context and this region may be problematic. However, selection of the data collection locations was based on seeking diversity in patronage and this is evident by the relatively diverse demographic nature of the sample.

It might be useful in future research to conduct in-depth interviews with potential tourists of ecotourism and other nature experiences as well as more mainstream tourism experiences to investigate, in more depth, consumer preferences and motivations for various tourism choices and determine if the apparent differences found in these results can be confirmed across a range of contexts and research approaches, not confined to survey based methodologies.

\section{CONCLUSION}


Tourism choices and the motivations for those choices vary according to the individual; however, there are, nevertheless, distinct commonalities in the motivations for choice of particular clusters of products, including ecotourism type products. Within this study the motivations for choosing ecotourism type experiences (across three separate forms) as a preferred holiday exhibit strong themes, namely: immersion in or communion with nature; education or learning about nature; and, in some cases, the ability to contribute personally to environmental conservation (e.g., volunteer ecotourism). Interestingly, these are surprisingly consistent with the elements of the industry based top down definitions of ecotourism and of accredited ecotourism venues. These themes are also uniquely distinct from those of the nonecotourism (ie. mainstream) holiday preferences, which revolve around more hedonistic type activities and pleasures (e.g., fun, relaxation, pampering, etc.). The results of this study suggest that ecotourism may also be at least partially demand driven (i.e., demand for nature as a focus of activities, and environmental learning an outcome), rather than being primarily supply driven as has been previously proposed. In other words, it appears that, at least in the case of their preferences for ecotourism type holidays, so called ecotourists are apparently motivated by internal wants and needs, rather than simply by a greening of the market (ie. eco-sell). If this is the case, then the potential ecotourist market segment, as one that is more environmentally interested and aware, might then expect environmental sustainability credentials of all tourism products and services, and make choices on the basis of those expectations. Given the evidence that the ecotourist market segment may be distinct from that of the mainstream tourist segment on the basis of patterns of interest and preference, future systematic investigation of ecotourists’ respective psychological profiles, including core values, beliefs, and relationship with nature, would add to our understanding of the socalled ecotourist, as consumer of environmentally sensitive tourism experiences. 


\section{REFERENCES}

Acott, T.G., La Trobe, H.L., \& Howard, S.H. (1998) An evaluation of deep ecotourism and shallow ecotourism. Journal of Sustainable Tourism 6(3), 238-253.

Blamey, R.K. \& Braithwaite, V.A. (1997). A social values segmentation of the potential ecotourism market. Journal of Sustainable Tourism, 5(1), 29-45.

Burns, A.C. \& Bush, R.F. (1995) Marketing Research. Englewood Cliffs, NJ: Prentice Hall.

Dolincar, S. \& Leisch, F. (2008). An investigation of tourists' patterns of obligation to protect the environment. Journal of Travel Research, 46, 381-391.

Dunlap, R. E., Van Liere, K. D, Mertig, A.G. \& Jones, R.E. (2000) Measuring endorsement of the New Ecological Paradigm: A revised NEP scale. Journal of Social Issue 56 (3), 425-442.

Eagles, P. F. J. (1992) The travel motivations of Canadian ecotourists. Journal of Travel Research 31(2): 3-7.

Ecotourism Australia (2008). Eco Certification Program.

http://www.ecotourism.org.au/neap.asp, retrieved 7 July 2008.

Fairweather, J. R., Maslin, C., \& Simmons, D. (2005). Environmental values and response to ecolabels among international visitors to New Zealand. Journal of Sustainable Tourism, 13(1), 82-98. 
Fennell, D. A. (2001) Areas and needs in ecotourism research. In D. B. Weaver (Ed.), The Encyclopedia of Ecotourism (pp. 639-653) Oxon, UK: CAB International.

Fennell, D.A. (2003) Ecotourism: An Introduction, $2^{\text {nd }}$ ed. London: Routledge.

Hawkins, D.E. \& Lamoureux, K. (2001). Global growth and magnitude of ecotourism. In D.B. Weaver (Ed.) The Encyclopedia of Ecotourism (pp. 63-72). Oxon, OX: CAB International.

Higham, J. \& Carr, A. (2002). Profiling tourists to ecotourism operations. Research Notes. Annals of Tourism Research, 29(4), 1168-1171.

Juric, B., Cornwell, T. B., \& Mather, D. (2002) Exploring the Usefulness of an Ecotourism Interest Scale. Journal of Travel Research 40(3), 259-269.

Luzar, E. J., Diagne, A., Gan, C. E. C., \& Henning, B. R. (1995) Evaluating nature-based Tourism Using the new Environmental Paradigm. Journal of Agricultural and Applied Economics 27(2), 544-555.

McKenzie-Mohr, D. (2000) Fostering sustainable behavior through community-based social marketing. American Psychologist 55(5), 531-537.

Page, S. J., \& Dowling, R. K. (2002) Ecotourism. Harlow, England: Pearson Education. 
Pitts, R. E., \& Woodside, A. G. (1986) Personal values and travel decisions. Journal of Travel Research 25(1): 20-25.

Rolston, H. I. (1991) Creation and recreation: Environmental benefits and human leisure. In Benefits of Leisure. Venture Publishing, Inc. State College, PA.

Schultz, P. W. (2001) The Structure of Environmental Concern: Concern for Self, Other People, and the Bioshpere. Journal of Environmental Psychology 21, 327-339.

Sharpley, R. (2001) The consumer behavior context of ecolabelling. In X. Font \& R. C. Buckley (Eds.). Tourism Ecolabelling: Certification and promotion of Sustainable Management. Wallingford, UK: CABI Publishing.

Sharpley, R. (2006) Ecotourism: A consumption perspective. Journal of Ecotourism 5(1\&2), $7-22$.

Thomas, S.J. (1999) Designing Surveys that Work. Thousand Oaks, California: Corwin Press, Inc.

Weaver, D. B., (2001a) Ecotourism as mass tourism: Contradiction or reality? Cornell Hotel and Restaurant Administration Quarterly (April), 104-112.

Weaver, D. B. (Ed.), (2001b) The Encyclopedia of Ecotourism. New York: CABI Publishing.

Weaver, D.B. (2006). Sustainable Tourism. Oxford: Elsevier Ltd. 
Wight, P.A. (1993). Ecotourism: Ethics or eco-sell? Journal of Travel Research, 31(3), 3-9.

Wight, P. A. (2001). Ecotourists: Not a homogeneous market segment. In D.B. Weaver (Ed.) The Encyclopedia of Ecotourism (pp. 37-62). Oxon, OX: CAB International.

Zografos, C., Allcroft, D. (2007). The environmental values of potential ecotourists: A segmentation study. Journal of Sustainable Tourism, 15 (1), 44-66. 
Table 1: Frequencies of Holiday Type Preferences ( $N=255$ )

Preferences

\begin{tabular}{|c|c|c|c|c|c|c|c|}
\hline Tourism Package & 1st & 2nd & 3rd & $4^{\text {th }}$ & 5th & 6th & Tot \\
\hline Mainstream sun and surf beach holiday (M1) & 83 & 55 & 40 & 41 & 28 & 8 & 255 \\
\hline Mainstream luxury resort holiday (M2) & 41 & 66 & 50 & 51 & 37 & 8 & 253 \\
\hline $\begin{array}{l}\text { Mainstream nightlife, gambling and shopping } \\
\text { holiday (M3) }\end{array}$ & 51 & 46 & 58 & 60 & 31 & 8 & 254 \\
\hline Ecotourism nature based holiday (E1) & 74 & 50 & 37 & 37 & 50 & 8 & 256 \\
\hline $\begin{array}{l}\text { Ecotourism wildlife watching and/or } \\
\text { photography holiday (E2) }\end{array}$ & 12 & 20 & 35 & 54 & 68 & 65 & 254 \\
\hline Ecotourism volunteer holiday package (E3) & 4 & 15 & 35 & 10 & 35 & 154 & 253 \\
\hline
\end{tabular}

$\mathrm{M}=$ Mainstream type $\mathrm{E}=$ Ecotourism type 
Table 2: Relationship between general interest in ecotourism (EI) and holiday preferences

\begin{tabular}{lc} 
Preference for ..... & $\begin{array}{c}\text { Average Ecotourism I nterest } \\
\text { (EI) }\end{array}$ \\
\hline Ecotourism holiday & $.48^{* * *}$ \\
Wildlife watching and photography holiday & $.46^{* * *}$ \\
Volunteer ecotourism holiday & $.36 * * *$ \\
Sun and surf beach holiday & $-.32 * * *$ \\
Luxury resort holiday & $-.47^{* * *}$ \\
Nightlife, shopping and gaming holiday & $-.35^{* * *}$ \\
\hline
\end{tabular}

$* * * \mathrm{p}<.001$ 
Table 3: Differences between ecotourist sample and mainstream sample in holiday first preferences

\begin{tabular}{lcccc} 
& $\begin{array}{c}\% \\
\text { Mainstream } \\
\text { venue } \\
\text { visitors }\end{array}$ & $\begin{array}{c}\text { Ecotourism } \\
\text { venue } \\
\text { visitors }\end{array}$ & $\chi^{2} \mathrm{~N}$ & Sig. level \\
\hline $\begin{array}{l}\text { Holiday preference } \\
\text { Ecotourism holiday }\end{array}$ & $33.3 \%$ & $58.2 \%$ & $15.22, \mathrm{~N}=253$ & .000 \\
$\begin{array}{l}\text { Wildlife watching \& photography } \\
\text { holiday }\end{array}$ & $31.3 \%$ & $50.5 \%$ & $9.38, \mathrm{~N}=254$ & .009 \\
$\begin{array}{l}\text { Volunteer ecotourism holiday } \\
\text { Sun and surf beach holiday }\end{array}$ & $9.8 \%$ & $17.6 \%$ & $5.184, \mathrm{~N}=254$ & .075 \\
$\begin{array}{l}\text { Luxury resort holiday } \\
\begin{array}{l}\text { Nightlife, gaming and shopping } \\
\text { holiday }\end{array}\end{array}$ & $63.2 \%$ & $38.0 \%$ & $18.44, \mathrm{~N}=255$ & .000 \\
\hline
\end{tabular}


Table 4: Correlations between holiday package preferences (Spearman's rho)

M1

M2

M3

E1

E2

E3

M1: Mainstream sun and surf beach holiday

Non Sig

M2 : Mainstream luxury resort holiday

$\begin{array}{lllll}.13 * & .35 * * & & \\ -.29 * * & -.56 * * & -.50 * * & \\ -.45 * * & -.43 * * & -.42 * * & .26 * * \\ -.36 * * & -.42 * * & -.50 * * & .25 * * & .21 * *\end{array}$

M3: Mainstream nightlife, gambling and shopping holiday

E1: Ecotourism nature based holiday

$.21 * *$ holiday

E3: Ecotourism volunteer holiday package

* Significant at 0.05 level (two-tailed)

** Significant at 0.01 level (two-tailed) 
Table 5 Motivation Frequencies

\begin{tabular}{|c|c|c|c|c|c|c|}
\hline Motivations & M1 & M2 & M3 & E1 & E2 & E3 \\
\hline Family togetherness/safety for children & 37 & 6 & - & 3 & 6 & - \\
\hline Fun & 14 & 2 & 1 & 2 & 5 & - \\
\hline Outdoors exercise & 21 & - & - & 10 & 7 & - \\
\hline Relaxation & 57 & 67 & - & 14 & 7 & 1 \\
\hline Adventures & - & - & - & - & 2 & - \\
\hline Love and value of nature & - & - & - & 19 & 21 & 3 \\
\hline Experiencing beauty of nature & - & - & - & 18 & 26 & - \\
\hline Education and learning & 1 & - & - & 16 & 26 & 9 \\
\hline Peace and tranquility & - & - & - & 22 & 4 & 1 \\
\hline
\end{tabular}

M1 = Mainstream sun and surf beach holiday

M2 = Mainstream luxury resort holiday

M3 = Mainstream nightlife, gambling and shopping holiday

$\mathrm{E} 1=$ Ecotourism nature based holiday

E2 = Ecotourism wildlife watching and/or photography holiday

$\mathrm{E3}=$ Ecotourism volunteer holiday package 
Figure 1. Pattern of Preferences for Ecotourism Holidays by Visitation

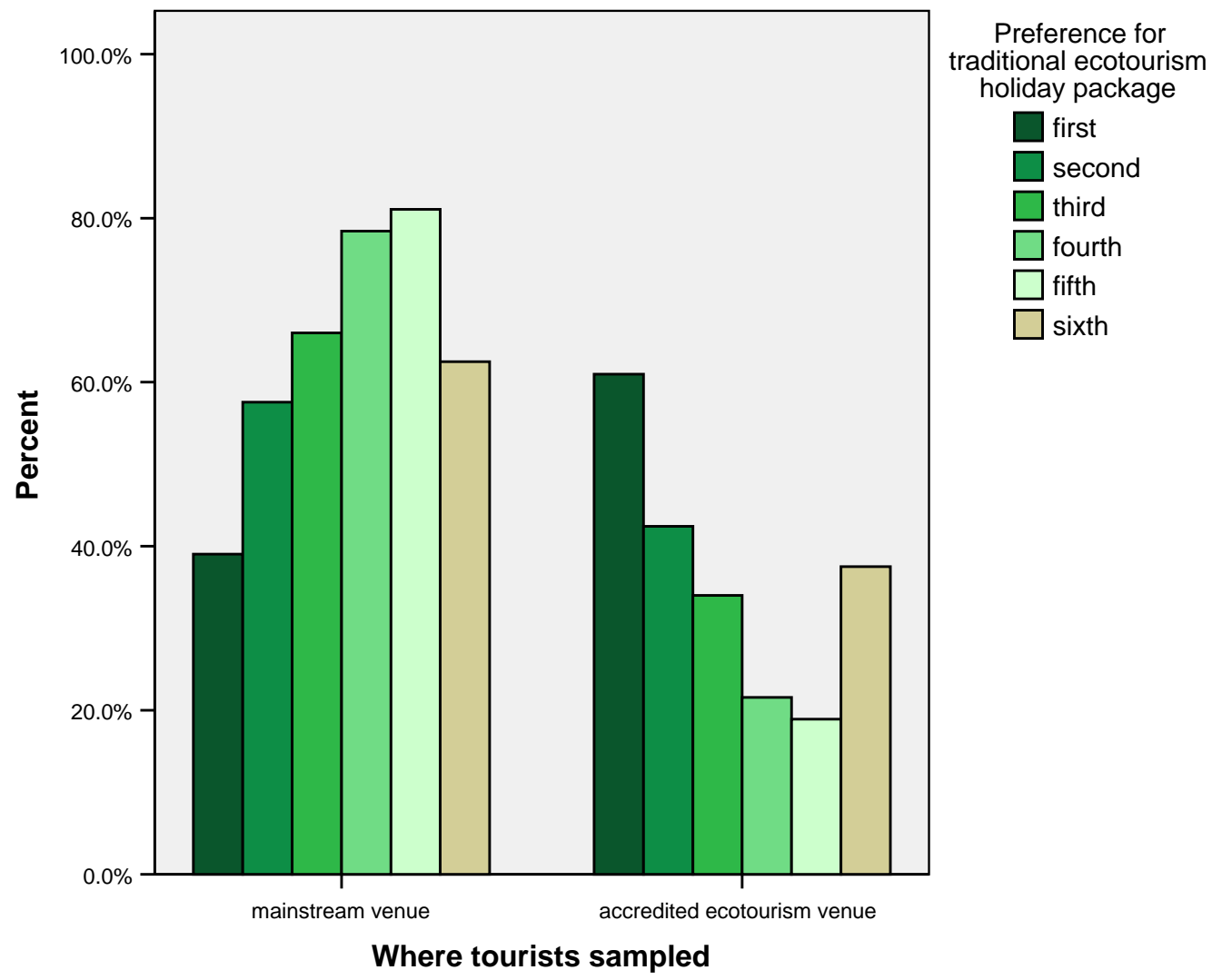

